\title{
Injuries Around the Proximal Interphalangeal Joint
}

Ruth En Si Tan, MBBS,

Andre Eu Jin Cheah, MBBS, MMed, MBA*

\section{KEYWORDS}

- Proximal interphalangeal joint $\bullet$ Fracture $\bullet$ Dislocation $\bullet$ Surgical fixation $\bullet$ Finger

\section{KEY POINTS}

- Proximal interphalangeal joint (PIPJ) injuries should not be underestimated because they can lead to notable loss of hand function.

- Treatment of PIPJ injuries should focus on stable, concentric joint reduction to achieve early mobilization.

- Surgical treatment should be adopted only when the expected outcomes are better than that of nonsurgical treatment.

Video content accompanies this article at http://www.plasticsurgery.theclinics.com.

\section{INTRODUCTION}

The proximal interphalangeal joint (PIPJ) is the most frequently injured joint in the hand. ${ }^{1}$ PIPJ injuries are challenging to treat due the joint's propensity for stiffness and late presentation, because it is not uncommon for these injuries to be dismissed at the initial presentation. With inadequate treatment, PIPJ injuries frequently lead to stiffness, deformity in the form of flexion contractures, and pain from premature degenerative arthritis. PIPJ injuries typically occur in young active individuals whose active lifestyles may be severely curtailed by a stiff and painful finger resulting in part from suboptimal treatment.

PIPJ injuries include

1. Ligamentous injuries: volar plate and/or collateral injuries

2. Intra-articular fractures
3. Subluxations or dislocations

4. A combination of the above

There are 3 main types of intra-articular fractures of the base of middle phalanx:

1. Dorsal fracture subluxations or dislocations

2. Volar fracture subluxations or dislocations

3. Pilon fractures

\section{ANATOMY, BIOMECHANICS, AND CLASSIFICATION}

The primary stability of the PIPJ is provided by its bony articular surface, the proper and accessory collateral ligaments, and the volar plate. Secondary stability is afforded by the flexor and extensor tendons.

The fracture pattern at the base of the middle phalanx depends on the direction of the force

Disclosure statement: Neither of the authors has any funding sources or commercial or financial conflicts of interest to declare.

Department of Hand and Reconstructive Microsurgery, National University Health System, Level 11, Tower Block, 1E Kent Ridge Road, 119228, Singapore

* Corresponding author.

E-mail address: andre_cheah@nuhs.edu.sg 
and position of the joint. ${ }^{2} \mathrm{~A}$ combination of longitudinal load and either hyperextension or hyperflexion causes dorsal or volar fracture dislocations, respectively. ${ }^{3,4}$ A predominantly axial load disrupts both the dorsal and volar cortices of the middle phalanx base, creating, by definition, a pilon fracture.

Fracture dislocations have been divided into stable, tenuous, and unstable categories. ${ }^{3,5,6}$ Previous biomechanical studies showed that the volar plate is the primary passive restraint against PIPJ hyperextension forces, ${ }^{7}$ whereas, more recently, Caravaggi and colleagues ${ }^{8}$ have suggested that the loss of bony restraint plays a much larger role compared with the collateral ligaments. As the debate continues regarding how much articular involvement leads to instability and how much flexion is required to keep the joint reduced, there is a general consensus that between $30 \%$ and $50 \%$ of articular involvement renders joint stability tenuous whereas more than $50 \%$ articular involvement indicates joint instability. ${ }^{3,5}$

\section{EVALUATION}

Initial assessment should include a thorough history, including chronicity and mechanism of injury. Physical examination should pay special attention to the stability of the PIPJ, with the use of local anesthesia if necessary. Lateral stability is tested in zero (for the proper collateral ligaments) and $30^{\circ}$ of flexion (for the accessory collateral ligaments). Radiological assessment with anteroposterior and true lateral films is crucial to diagnosis of PIPJ injuries. When there is joint subluxation, a $V$ sign is seen, which describes an asymmetric joint space seen on a true lateral radiograph ${ }^{9}$ (Fig. 1).

Features to note on radiographs include ${ }^{10}$

1. Percentage of articular surface involvement

2. Articular step or gap

3. Comminution or fragmentation

4. Number of fracture fragments

5. Joint subluxation or dislocation

An estimate of the involved articular surface from plain radiographs enables classification of fractures according to their stability and serves as a guide to treatment. The degree of articular comminution ${ }^{10}$ and size of fracture fragment, however, were found to be underestimated. ${ }^{11}$ One possible reason suggested was that fractures entered the joint at varying angles that were difficult to assess with standard radiographs. Hence, oblique radiographs or advanced imaging may provide further insight into the severity of an injury. In pilon fractures, neither the initial degree of

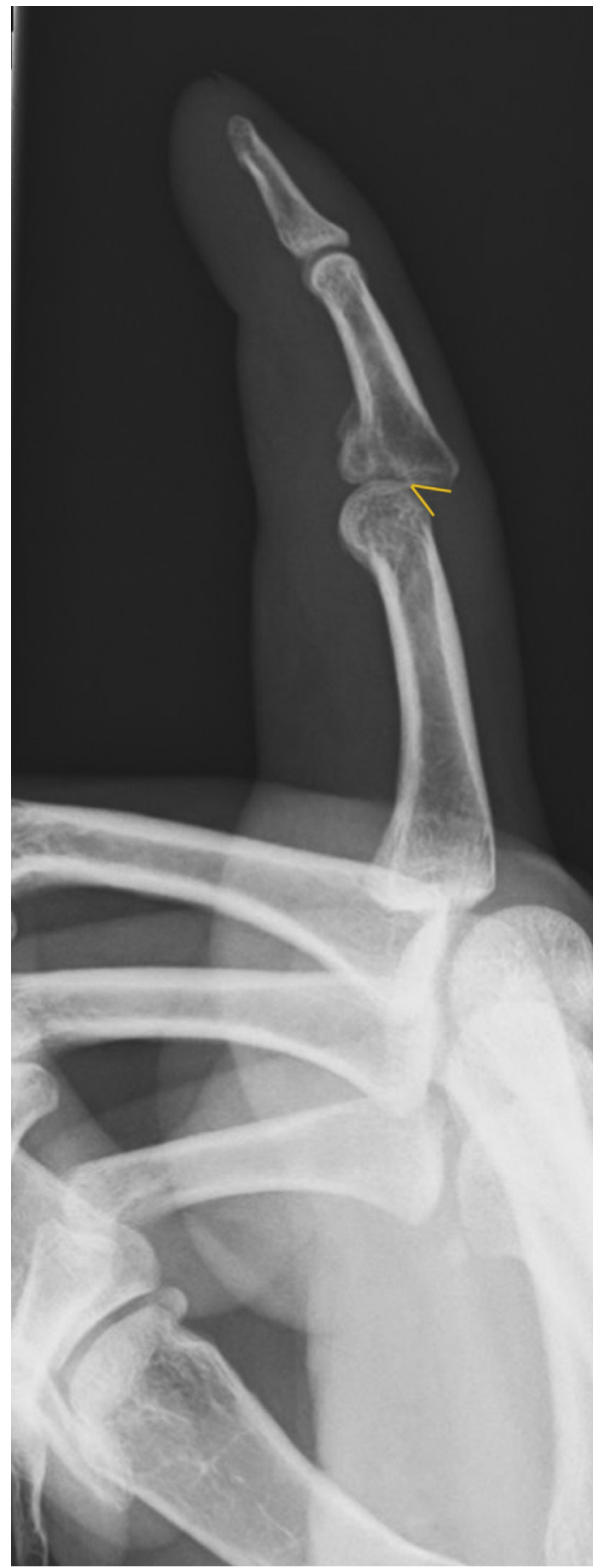

Fig. 1. Lateral radiograph of the PIPJ with a dorsal fracture subluxation demonstrating a $\mathrm{V}$ sign (yellow lines).

radiographic displacement nor any findings on CT help determine the need for surgery. Due to their configuration, pilon fractures are unstable and prone to collapse if not supported. 


\section{GOALS OF TREATMENT}

The main aim in treatment of PIPJ injuries is to achieve a stable joint for early mobilization. ${ }^{3,12,13}$ This is important to prevent stiffness. Although anatomic restoration of the joint surface is a desirable goal, it is not the foremost priority.

Joint stability is achieved through ${ }^{3,14-20}$

1. Concentric joint reduction - this enables gliding motion of the joint without hinging, which occurs when there is joint subluxation.

2. Restoration of stabilizers-this may include both bony and soft tissue stabilizers of the PIPJ.

\section{TREATMENT OF PROXIMAL \\ INTERPHALANGEAL JOINT COLLATERAL LIGAMENT INJURIES}

Collateral ligament injuries of the PIPJ are common and may be classified into grades I, II and III injuries. More than $20^{\circ}$ of deformity on the lateral stress test in extension indicates complete collateral ligament injury with involvement of at least 1 other secondary stabilizer, such as the volar plate, bony anatomy, or accessory collateral ligament.

Grades I and II injuries may be treated nonsurgically, with short-term immobilization in a splint followed by early buddy taping, whereas operative treatment may be considered for grade III injuries. This is still a topic of controversy, however, with some investigators advocating repair only if there is subluxation and closed reduction is not possible, whereas others report that surgical repair is necessary, ${ }^{21}$ especially in young workers and athletes. ${ }^{22-24}$

Collateral ligaments typically fail proximally. If there is enough substance of the collateral ligament on the condyle of the proximal phalanx, it may be repaired directly. Otherwise, a microsuture anchor may be used. Lee and colleagues ${ }^{25}$ found that operative repair of grade II radial collateral ligament injuries resulted in lower pain score, more rapid recovery of finger motion, and better appearance of the PIPJ compared with nonsurgical treatment at short-term followup.

Although conservative treatment may achieve goals of joint stability and range of motion (ROM), operative treatment carries the advantage of allowing earlier ROM and decreased swelling. Surgical intervention should be balanced against a patient's needs and risk of complications, such as skin irritation from the suture anchor knot.

\section{TREATMENT OF PROXIMAL INTERPHALANGEAL JOINT DISLOCATIONS}

PIPJ dislocations are classified as dorsal, volar, lateral, or rotatory, depending on the position of the middle phalanx relative to the proximal phalanx. ${ }^{26,27}$ Dorsal and lateral dislocations are the most common and usually can be reduced in a closed fashion. Lateral dislocations frequently have a dorsal component. ${ }^{28}$ Volar and rotatory dislocations are rare injuries and are irreducible usually by closed methods due to interposition of soft tissue, which requires open reduction.

Suspicion is required for patients who report rotatory traction injury. ${ }^{28}$ Puckering of the skin on clinical examination suggests soft tissue interposition. ${ }^{27}$ Ultrasound or MRI facilitates assessment of the soft tissue injury involved.

\section{Closed Reduction}

Closed reduction is attempted under local anesthesia. Dorsal and dorsolateral dislocations are reduced with gentle longitudinal traction accompanied by pressure on the base of the middle phalanx. This prevents entrapment of the collateral ligament or volar plate. Reduction of volar and rotatory dislocations is attempted with the metacarpophalangeal joint and PIPJ flexed to relax the entrapped extensor apparatus. ${ }^{27}$

\section{Open Reduction}

Open reduction should be performed as soon as possible to avoid joint contracture, fibrosis, and adhesions. Dorsal dislocations commonly are dealt with via a volar or lateral approach. The volar plate may be interposed in the joint, ${ }^{29}$ or the head of the proximal phalanx may penetrate volar soft tissues or flexor tendon in a buttonhole mechanism. ${ }^{30,31}$

Volar dislocations are more serious injuries. Reduction may be blocked due to entrapment of the volar plate, ${ }^{32}$ central slip, ${ }^{33}$ lateral band, ${ }^{34}$ collateral ligaments, ${ }^{35}$ or fracture fragment. ${ }^{36}$ An axial compression force with rotational element brings the lateral band of the extensor tendon on the volar side of the head of the proximal phalanx and remains entrapped in the joint. ${ }^{37}$ Open reduction usually is via a dorsal or lateral approach.

Repair of ruptured collateral ligaments with microsuture anchors is beneficial for early ROM, whereas volar plate avulsions are treated more commonly with extension block splinting or buddy taping. Repair of the central slip should be performed routinely to prevent boutonniere deformity. ${ }^{26,27,38}$ 


\section{TREATMENT OF PROXIMAL INTERPHALANGEAL JOINT FRACTURE DISLOCATIONS}

Stable PIPJ injuries are commonly treated nonsurgically, with extension block splinting or buddy taping. There is no universally accepted treatment, however, of unstable fracture dislocations of the PIPJ. ${ }^{39}$ In a survey of surgeons using lateral radiographs of the PIPJ, Janssen and colleagues ${ }^{10}$ found that there was substantial agreement when deciding for operative versus nonoperative treatment, but there was variation regarding which surgical technique to use for the same fracture. Articular step or gap greater than $2 \mathrm{~mm}$ and joint subluxation or dislocation were associated most strongly with a decision for operative treatment.

Myriad surgical treatment options have been described for unstable PIPJ injuries. Mean PIPJ ROM using various approaches has been reported to be approximately $80^{\circ}$, and there is little difference between the efficacy of these methods. ${ }^{40}$ If operative treatment is chosen, the outcomes of the chosen procedure should match or be better than that expected of conservative treatment. Table 1 summarizes the indications of current treatment options.

\section{Pinning}

The advantage of the pinning method is its simplicity and ability to maintain an extension block angle more securely compared with a splint. ${ }^{41}$ Newington and colleagues ${ }^{42}$ suggested that accurate anatomic reduction of the fracture itself is not required, provided a congruous and concentric reduction of the PIPJ is achievedthis is the main goal of percutaneous pinning. An anatomically imperfect joint surface associated with radiological degenerative changes may still have a good clinical outcome and may not always affect the ROM. ${ }^{42-45}$ Complications include recurrent subluxation and pin track infection. ${ }^{46}$

\section{Extension block pinning}

First described by Inoue and Tamura, ${ }^{47}$ extension block pinning involves closed reduction of the dorsal fracture dislocation and drilling of a

Table 1

Current practices in treatment of proximal interphalangeal joint fracture dislocations

\begin{tabular}{|c|c|c|c|}
\hline Method & Indications & Contraindications & $\begin{array}{l}\text { Typically Used for } \\
\text { Chronic Injuries }\end{array}$ \\
\hline $\begin{array}{l}\text { Percutaneous pinning } \\
\text { Extension block } \\
\text { Across the PIPJ }\end{array}$ & $\begin{array}{l}\text { Can be used when a quick } \\
\text { and simple method is } \\
\text { desired or if soft tissue is } \\
\text { unstable prohibiting an } \\
\text { open approach }\end{array}$ & $\begin{array}{l}\text { Fractures involving the } \\
\text { dorsal cortex of the } \\
\text { middle phalanx base }\end{array}$ & No \\
\hline Interfragmentary screw & Large fragments & Severe comminution & No \\
\hline $\begin{array}{l}\text { Plate and screws } \\
\text { Volar plate } \\
\text { With raft screws } \\
\text { Buttress alone } \\
\text { Dorsal plate } \\
\text { Lateral plate }\end{array}$ & $\begin{array}{l}\text { Large to comminuted } \\
\text { fracture fragments } \\
\text { Pilon fractures } \\
\text { Comminuted fragments } \\
<50 \% \text { of phalangeal base, } \\
\text { which are too small for an } \\
\text { interfragmentary screw } \\
\text { Pilon fractures } \\
\text { Volar fracture dislocations } \\
\text { Pilon fractures }\end{array}$ & $\begin{array}{l}\text { For a pure buttress volar } \\
\text { plate, there should not be } \\
\text { a fracture involving the } \\
\text { dorsal cortex of the } \\
\text { middle phalanx base }\end{array}$ & No \\
\hline External fixation & $\begin{array}{l}\text { Comminuted volar, dorsal } \\
\text { lip or pilon fractures of } \\
\text { the middle phalanx base } \\
\text { Augmentation of other } \\
\text { surgical methods }\end{array}$ & $\begin{array}{l}\text { Concomitant fractures } \\
\text { involving the proximal } \\
\text { and middle phalanx }\end{array}$ & Yes \\
\hline $\begin{array}{l}\text { VPA } \\
\text { HHA }\end{array}$ & $\begin{array}{l}\text { Large volar base defect } \\
\text { Comminuted volar lip } \\
\text { fractures (not amenable } \\
\text { to fixation) }\end{array}$ & $\begin{array}{l}\text { Fractures involving the } \\
\text { dorsal cortex of the } \\
\text { middle phalanx base or } \\
\text { proximal phalangeal head } \\
\text { fracture } \\
\text { Preexisting PIPJ } \\
\text { osteoarthritis }\end{array}$ & $\begin{array}{l}\text { Yes } \\
\text { Yes }\end{array}$ \\
\hline
\end{tabular}


Kirschner (K) wire into the distal, dorsal aspect of the proximal phalanx to block the terminal extension and prevent dorsal dislocation ${ }^{41,46,48,49}$ (Fig. 2). Typically, a $1.2-\mathrm{mm}$ or $1.4-\mathrm{mm} \mathrm{K}$ wire is inserted at an angle dorsal to the coronal plane through or beside the central slip into the distal dorsal aspect of the proximal phalanx. ${ }^{46}$ Percutaneous intramedullary fracture reduction, ${ }^{50}$ closed reduction and pinning of the volar fragment, ${ }^{49}$ or open reduction and pinning of fragments ${ }^{46}$ may be performed together with extension block pinning. Postoperatively, flexion of the PIPJ is allowed with extension limited by the $\mathrm{K}$ wire. The $\mathrm{K}$ wire is removed after an average of 3 weeks. ${ }^{41,46}$

\section{Pinning across the proximal interphalangeal joint}

Another method of pinning involves transfixing of the PIPJ (see Fig. 2), using a $\mathrm{K}$ wire inserted from the dorsum of the base of the middle phalanx just distal to the central slip insertion and then passed proximally across the PIPJ joint into the proximal phalanx head with the PIPJ in $30^{\circ}$ to $60^{\circ}$ of flexion. ${ }^{42,45,51}$ Postoperatively, the $\mathrm{K}$ wire is removed after 4 weeks ${ }^{45}$ and active ROM of the PIPJ commenced thereafter.

Satisfactory outcomes have been reported despite the PIPJ being in slight dorsal subluxation, especially when the middle phalanx heals in a position that restores the concavity of the phalangeal base. ${ }^{18,43,45,51,52}$ If the palmar fragment does not heal, the joint is more likely to hinge and not glide normally.

\section{Open Reduction and Internal Fixation}

Open reduction and internal fixation (ORIF) ideally allows for anatomic reduction of the joint and articular fragments, while restoring stability with the crucial volar lip buttress and allowing early ROM. Reducing the articular surface (for example, a central depressed fragment) may prevent secondary osteoarthrosis ${ }^{40}$ but is less crucial. Factors influencing the results after ORIF include patient age, size of palmar fragment, chronic cases, period of immobilization after surgery, and recurrence of subluxation. The most significant factor influencing PIPJ joint ROM after surgery is postoperative early motion, with a second factor patient age. ${ }^{40}$

Various methods of internal fixation have been described-dorsal and volar plating, ${ }^{53,54}$ buttress plating, ${ }^{40}$ hook plating, ${ }^{55}$ and screw fixation from volar $^{19,51,56}$ and dorsal ${ }^{57}$ approaches, After internal fixation, splint immobilization, extension block pinning, or an external fixator may be used to augment the fixation. ${ }^{40}$ Techniques for fixation of small fragments include $\mathrm{K}$ wires, ${ }^{20,22,58,59}$ miniscrews, ${ }^{56,60,61}$ pull-out sutures with tension banding, 3,17 and a combination of these techniques (Fig. 3). The volar approach to the PIPJ commonly is used (Video 1). ${ }^{62}$

Interfragmentary screws are indicated for larger fracture fragments, whereas plate fixation is more suited to comminuted fragments. ${ }^{63}$ Volar plate fixation uses the principle of buttressing to maintain fracture reduction, with screws to maintain the intra-articular surface. ${ }^{53}$ The addition of a plate, as opposed to screw fixation alone, provides a wider surface to hold the fragments in reduction, especially smaller ones. ${ }^{53,64}$ The proximal part of the plate can be fashioned into a hook and wrapped around the small fragments that remain attached to the volar plate, which reduces comminuted fragments (Fig. 4). ${ }^{53}$ Placement of screws in the diaphysis of the middle
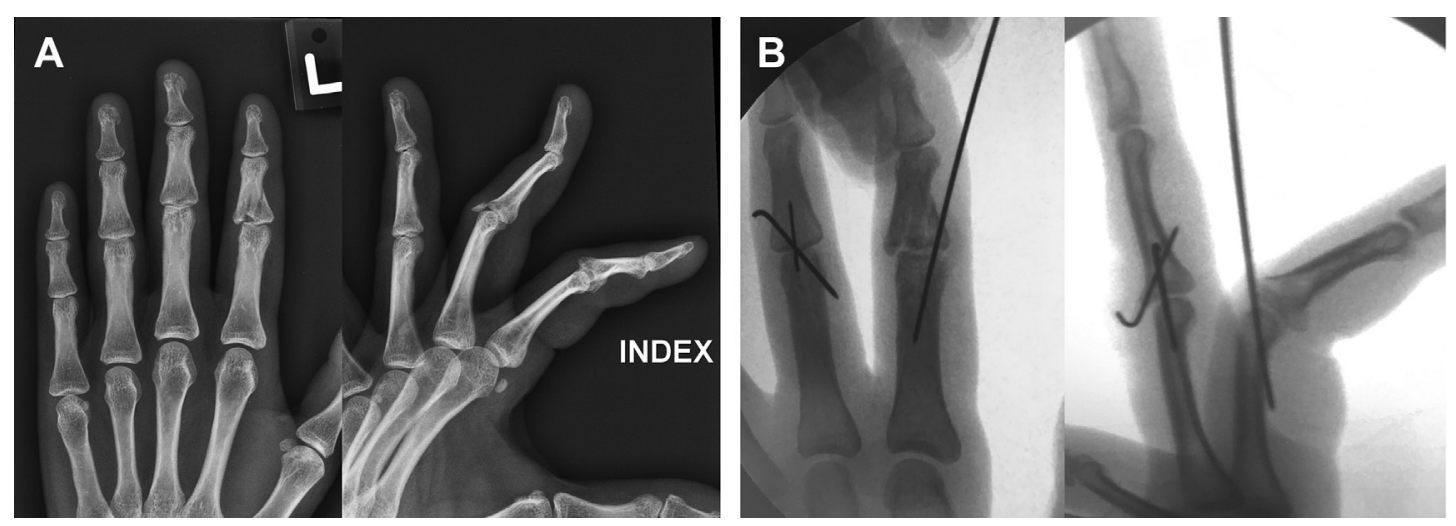

Fig. 2. PA (left) and lateral (right) radiographs of a patient who sustained a PIPJ dorsal fracture subluxation of the index finger and volar fracture dislocation of the middle finger $(A)$ who underwent fixation of index finger with an extension block $\mathrm{K}$ wire, and fixation of middle finger with a $\mathrm{K}$ wire transfixing the PIPJ and percutaneous pinning of the dorsal lip fragment $(B)$. The left and right panels show the PA and lateral radiographs respectively. 
A

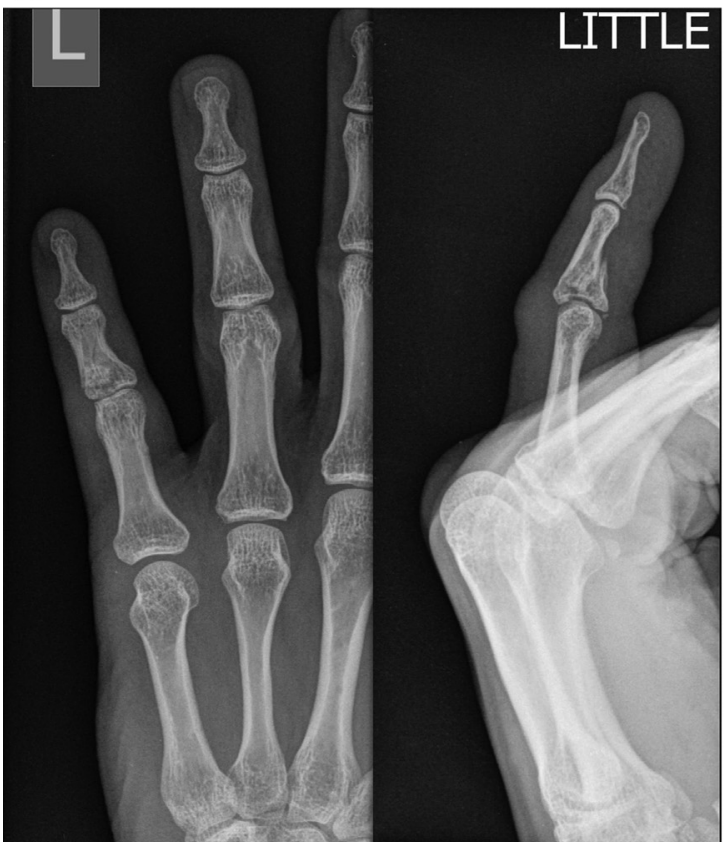

B

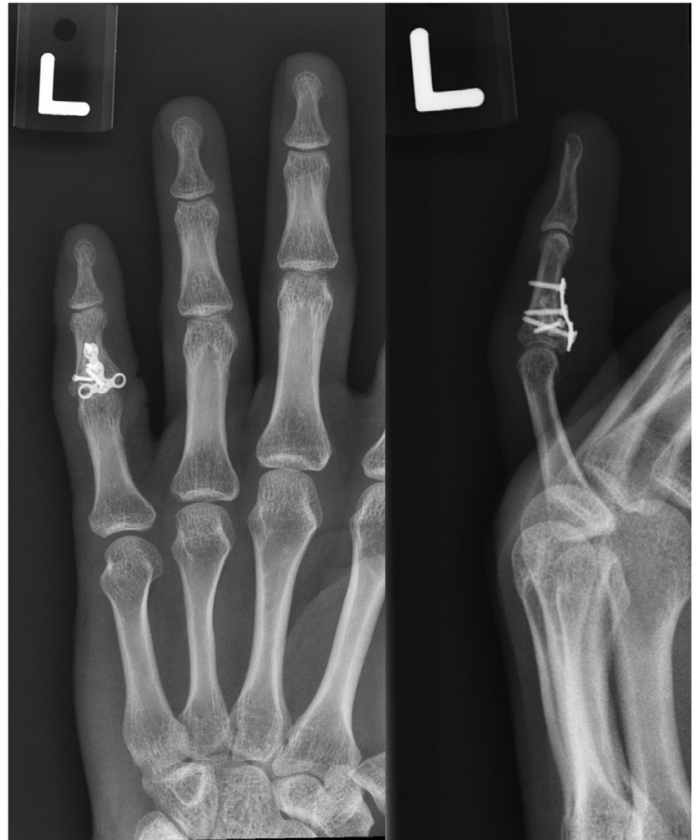

Fig. 3. PA and lateral radiographs on the right and left pane respectively of a patient with unstable PIPJ dorsal fracture subluxation with a centrally depressed fragment. $(B)$ PA and lateral radiographs shown in the right and left panel respectively of the same patient underwent ORIR with combination of miniscrew fixation and volar plating.

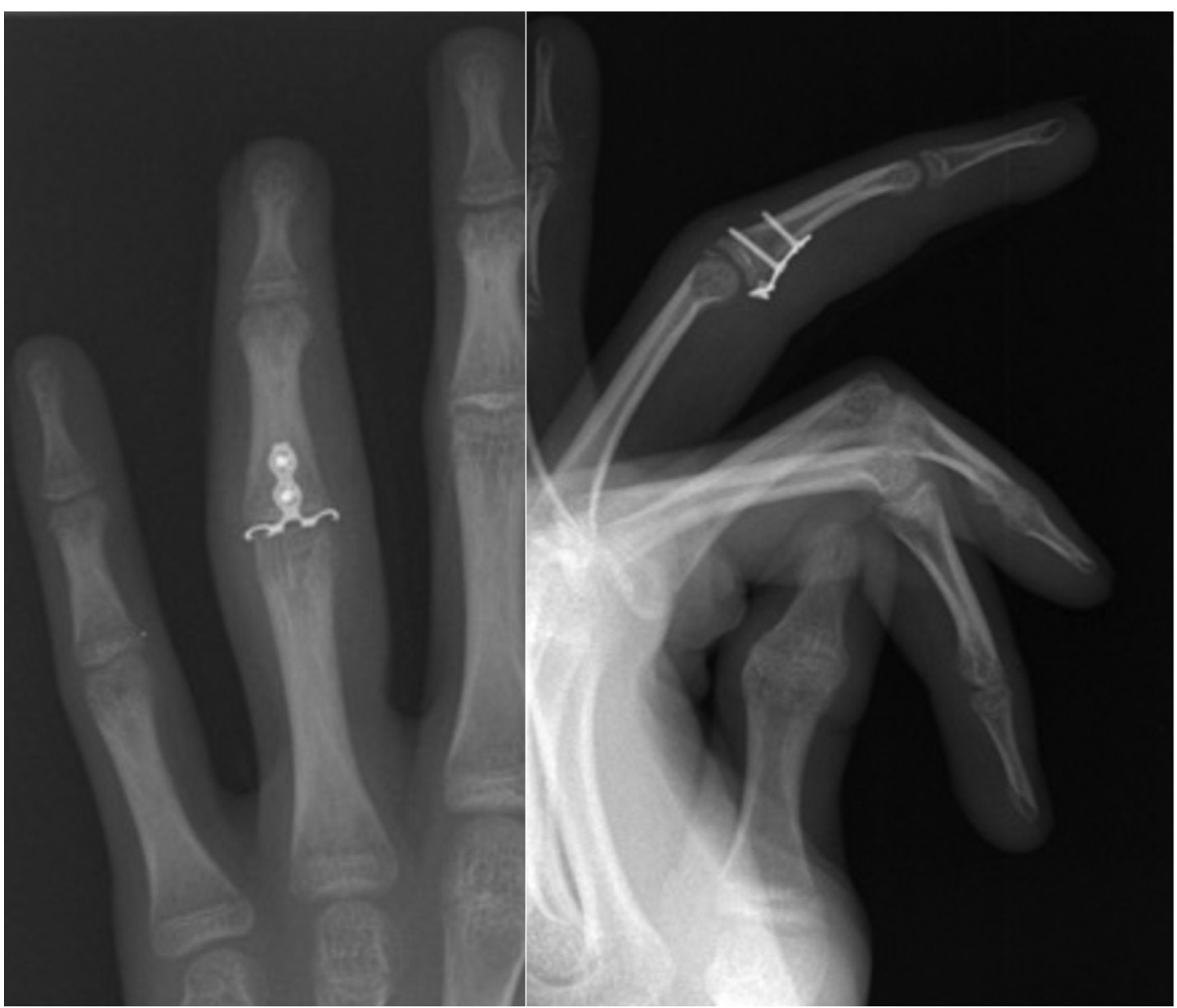

Fig. 4. PA and lateral radiographs on the left and right panels respectively demonstrating the usage of a volar hook plate technique. 
phalanx distally adds to stability without affecting the viability of the fracture fragments; the subchondral screws provide structural support for centrally depressed fragments, which have been reduced. ${ }^{53,54}$ The availability of smaller implants in recent years has facilitated this technique of ORIF. ${ }^{64}$ Foo and colleagues ${ }^{63}$ demonstrated that a plate and screw construct showed the greater resistance to displacement and implant failure compared with interfragmentary screws or a buttress plate alone. Flexion contracture due to flexor tendon adhesion after palmar plating can occur ${ }^{40,53,54}$ and may necessitate secondary surgery for implant removal and tenolysis.

\section{External Fixation}

Many types of external fixators have been described, including static ${ }^{65}$ or dynamic. ${ }^{2,16,66-77}$

Dynamic distraction external fixation makes use of ligamentotaxis through distraction to obtain and maintain fracture reduction. Static external fixators have fallen out of fashion in favor of dynamic ones that allowed early active motion to achieve better clinical outcomes. ${ }^{72}$ An ideal external fixator maintains congruent joint surfaces, reduces the fracture by ligamentotaxis, is low profile, prevents compression forces, and allows immediate active motion. ${ }^{2}$ The distraction is based off a transverse wire through the axis of the PIPJ rotation in the head of the proximal phalanx (Fig. 5).

A biomechanical study found that less traction is required to keep the joint reduced with increased flexion of the PIPJ. ${ }^{6}$ Importantly, the investigators found that with the PIPJ in full extension, no amount of force could keep the joint reduced in unstable dorsal fracture dislocations. Hence, an optimal PIPJ flexion angle of $20^{\circ}$ was suggested to maintain joint reduction while minimizing risk of flexion contracture. For unstable dorsal fracture dislocations, modalities that do not restore the bony volar lip (such as splint and external fixation) need to have an element of dorsal blocking in their design. Otherwise, there is persistent subluxation when the PIPJ is in full extension. In contrast, when internal fixation restores the bony volar lip of the middle phalanx, extension blocking is not required because the bony buttress maintains reduction of the joint. ${ }^{6}$

\section{Volar Plate Arthroplasty}

Originally described by Eaton and Malerich ${ }^{18}$ in 1980 for treatment of acute and chronic PIPJ dorsal fracture dislocations up to 2 years after injury, volar plate arthroplasty (VPA) aims to resurface the fractured surface of the middle phalanx base
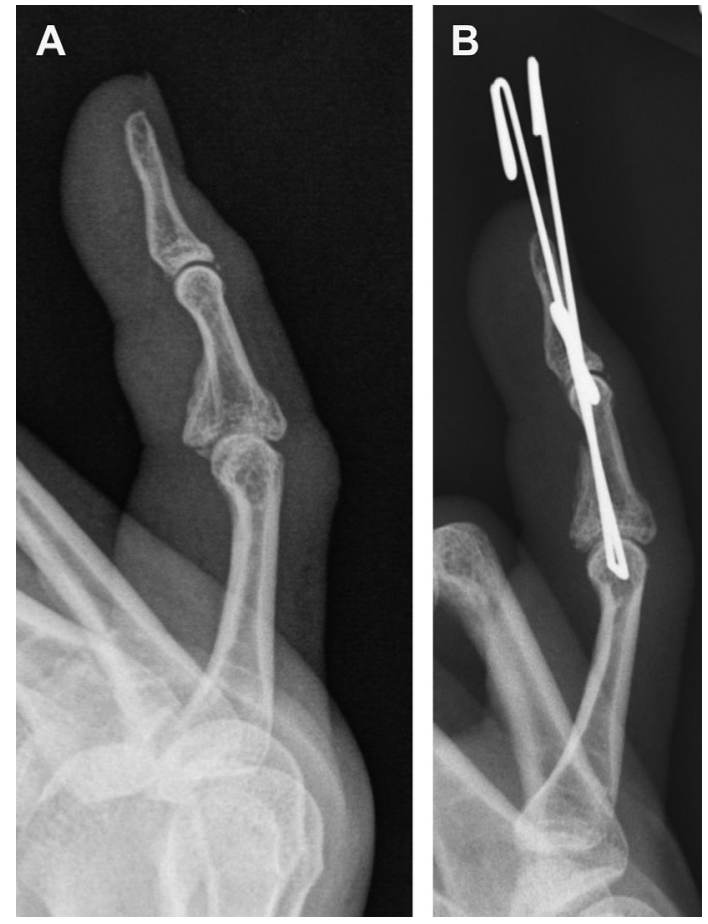

Fig. 5. (A) Radiographs of a patient who sustained a pilon fracture. (B) Distraction external fixation enabled restoration of joint congruity. (Courtesy of Sandeep J Sebastin.)

with the volar plate while providing a restraint to dorsal subluxation. Interposition of other types of soft tissue into the PIPJ has been described, including fat, tendon, and periosteum. ${ }^{78}$

The PIPJ is exposed via a shotgun approach after mobilization of the neurovascular bundles. The volar plate is incised along its most lateral (from the collaterals) and distal margins (from the base of the middle phalanx), creating a flap that is as broad and long as possible. ${ }^{79}$ The volar plate is attached to the most dorsal part of the articular defect after fashioning of a trough. This trough should be perpendicular to the long axis of the middle phalanx to prevent angular deformity and asymmetric collapse. ${ }^{18}$ Sutures are attached to radial and ulnar sides of the volar plate and passed as a pullout suture over the dorsum of the middle phalanx. There should be smooth articular contour from the base of the middle phalanx to the volar plate.

Complications include angular deformities, ${ }^{18,79,80}$ flexion contracture of PIPJ and distal interphalangeal joint (DIPJ), ${ }^{4,80}$ pin and wire tract infections, redisplacement, and recurrent subluxation. $4,9,80$ VPA has a tendency for flexion deformity, which increases with an increasing defect in the middle phalanx palmar base as the volar plate is advanced further into the joint. ${ }^{81}$ Mild flexion contractures of the DIPJ $10^{\circ}$ to $20^{\circ}$ are common and expected, 
but more severe flexion contractures can occur if the joint is immobilized in excessive flexion or if the volar plate is insufficiently mobilized..$^{81}$

\section{Hemi-Hamate Replacement Arthroplasty}

Hemi-hamate replacement arthroplasty (HHA) has several characteristics that fulfill the treatment goals of PIPJ dorsal fracture dislocations. ${ }^{81}$ It provides a stable bony palmar lip, enables early motion through rigid fixation, and restores native hyaline cartilage.

Originally described by Hastings ${ }^{82,83}$ in 1999 , with clinical results published in 2003, the hemihamate autograft reconstruction of the middle phalanx base is a technically challenging procedure that aims to restore joint congruity by replacing the damaged volar lip of the middle phalanx. The configuration of the hamate (dimensions, central ridge, and bicondylar facets) mimics the base of the middle phalanx volar lip. Reconstruction of the articular surface can be difficult in comminuted fractures, hence the usefulness of a graft. ${ }^{39}$ It is more technically demanding than ORIF. Consequently, it may be reasonable to first attempt ORIF and then proceed to HHA when excessive comminution precludes ORIF.

Radiographs of a young patient with a malunited right middle finger PIPJ dorsal fracture dislocation are shown in Fig. 6. After shot-gunning the joint with the PIPJ hyperextended, the extent of volar lip involvement is assessed (Fig. 7) and removed to create a recipient site for the hemi-hamate graft (Fig. 8). The size of the graft required is measured in 3 planes. An incision is made over the fourth and fifth carpometacarpal joints in the same hand (Fig. 9) and a graft of appropriate size is harvested from the dorsal distal part of the hamate (Fig. 10). After harvesting, the graft is further contoured to match the recipient site accurately. The graft then is fixed with at least 2 lag screws (Figs. 11 and 12). The volar plate is repaired.

Most investigators recommend early active motion (between 1 day and 2 weeks) ${ }^{39,82-86}$ with an extension block splint to prevent tendon adhesion and joint contracture. Subsequently, patients are allowed full active ROM of the joint after radiographic graft union. It has been recommended to wait 4 months before active loads are placed on joint. $^{39}$

Overall complication rate was $35 \%$, of which osteoarthritis is a major concern and reported as a radiological finding in up to $50 \%$ of the cases. ${ }^{82,84,85}$ Possible reasons for this include denervation and poor vascularization, to which Rozen and colleagues ${ }^{87}$ proposed a vascularized hemi-hamate free flap. Other complications

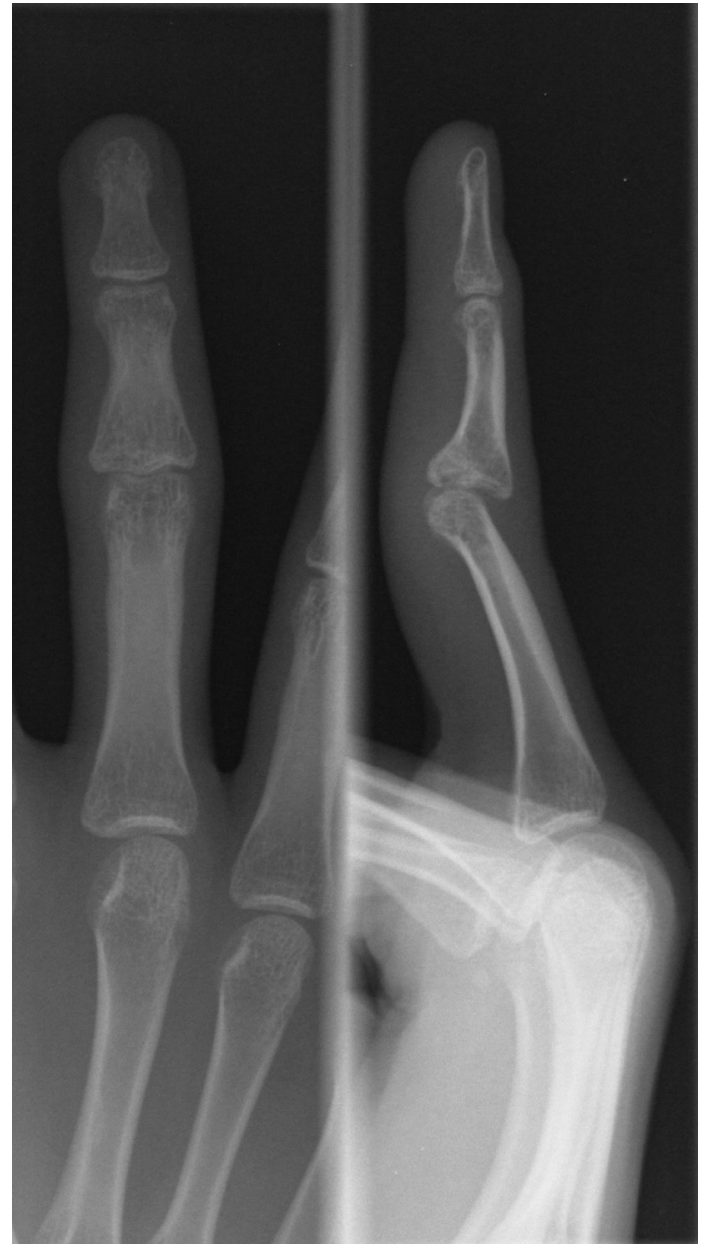

Fig. 6. PA and lateral radiographs in the left and right panes respectively of a patient with malunited PIPJ dorsal fracture dislocation. (Courtesy of Mark $E$ Puhaindran.)

include PIPJ joint contracture (present in up to $10 \%$ of patients) and graft resorption. Donor site morbidity generally is low.

\section{Volar Fracture Dislocations}

Volar fracture dislocations are associated with a dorsal lip or central slip fracture, with or without disrupting of the central slip and/or collateral ligaments. They are far less common than dorsal fracture dislocations and usually have worse outcomes with a delay to treatment due to failure of early diagnosis. ${ }^{88}$ These injuries can range from complete dislocation of the PIPJ with disruption of the intra-articular surface to mild subluxation with a small dorsal lip fragment. With attenuation of the central slip, these injuries can progress to a boutonniere deformity. 


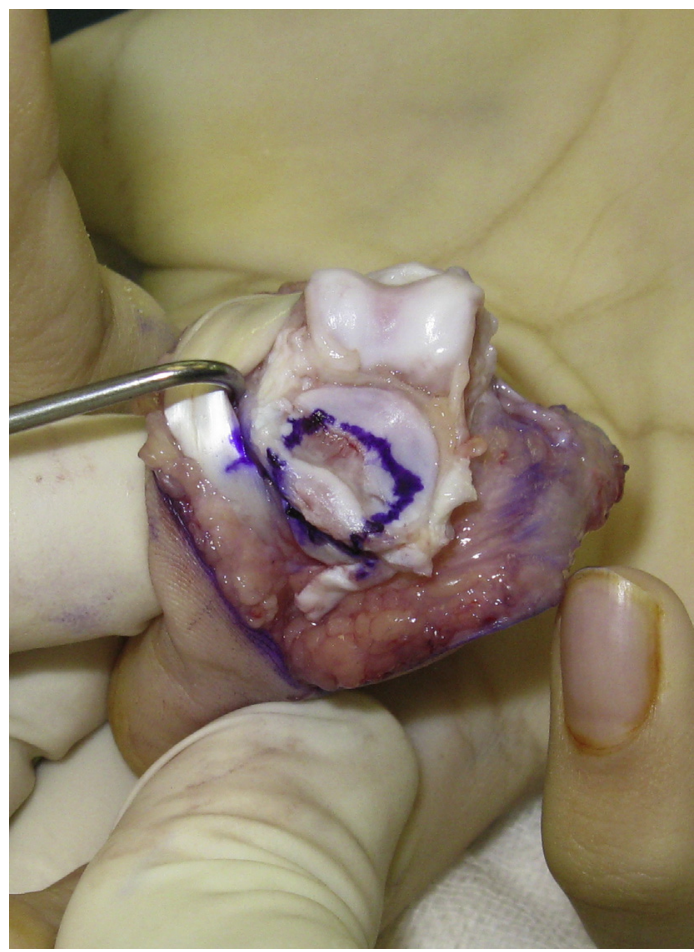

Fig. 7. Area of the involved middle phalanx base with unhealthy cartilage marked out (purple line). (Courtesy of Mark E Puhaindran.)

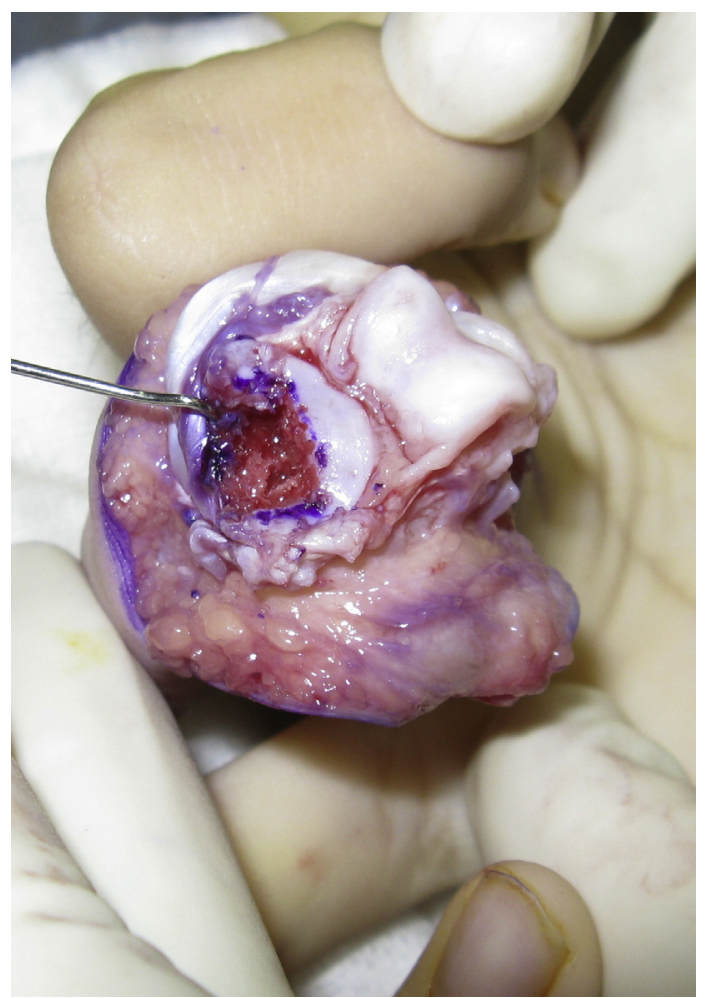

Fig. 8. Recipient site for hemi-hamate graft prepared using K-wire drill holes and osteotomes. (Courtesy of Mark E Puhaindran.)

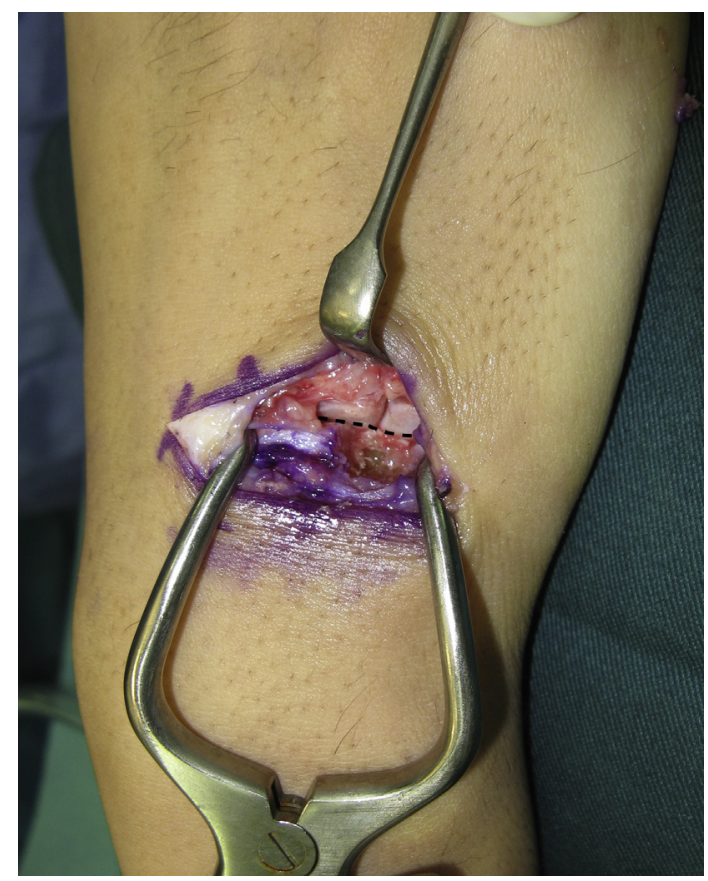

Fig. 9. Harvest of the hemi-hamate autograft (fourth and fifth CMCJ joint line is marked on the figure with a dotted line). (Courtesy of Mark E Puhaindran.)

Although there currently is no classification to describe or guide treatment, strategies follow the same principles as dorsal fracture dislocations with focus on early ROM. These include splinting in extension, closed reduction, and percutaneous

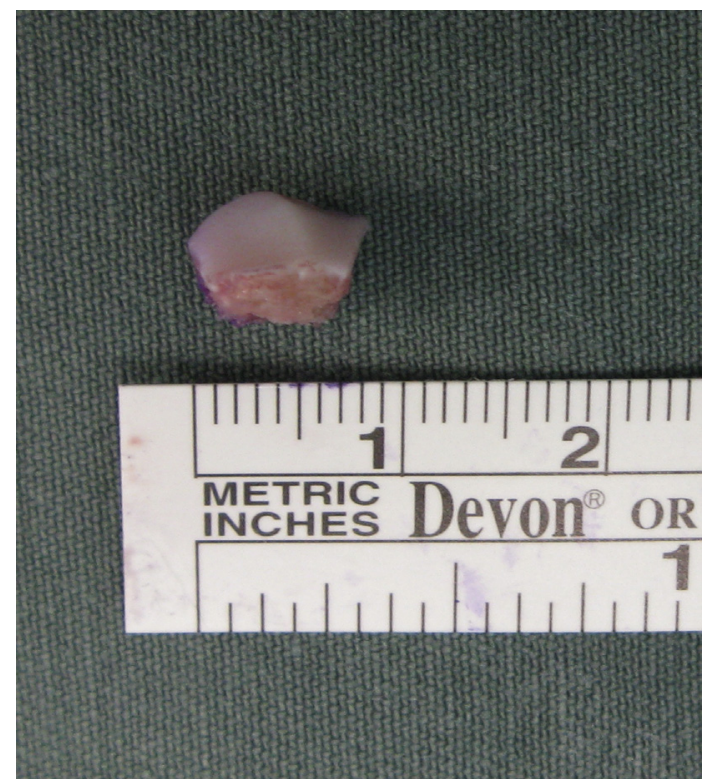

Fig. 10. The shape of the hemi-hamate autograft is similar to the base of the middle phalanx. (Courtesy of Mark E Puhaindran.) 


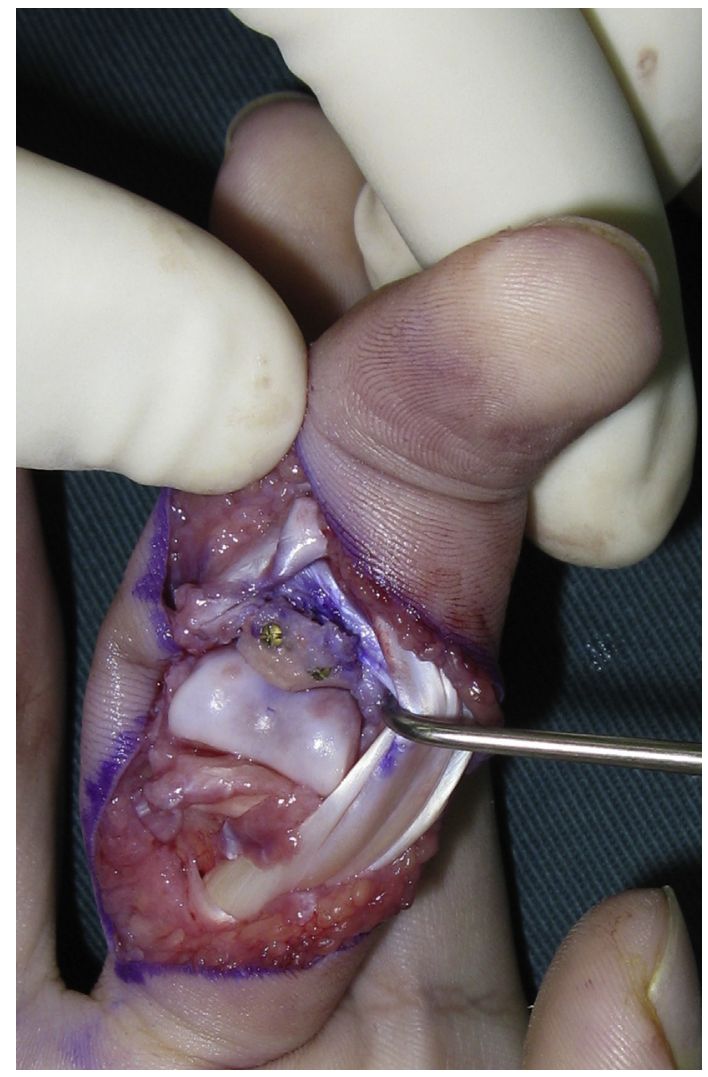

Fig. 11. Fixation was performed with 2 screws. (Courtesy of Mark E Puhaindran.)

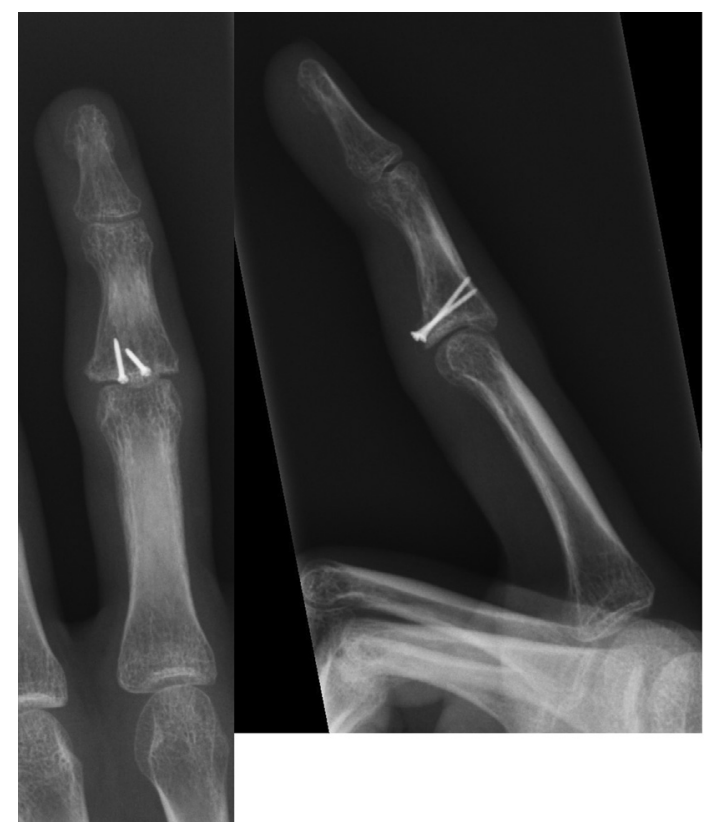

Fig. 12. PA and lateral radiographs shown in the right and left panels respectively demonstrating union of the hemi-hamate autograft and restoration of the PIPJ joint surface. (Courtesy of Mark E Puhaindran.) pinning, ${ }^{88,89} \mathrm{~K}$-wire transfixion of the PIPJ, ${ }^{88}$ external fixation, ${ }^{89}$ miniplate or hook plate fixation, ${ }^{55,90}$ screw fixation, ${ }^{89,91}$ loop wire, ${ }^{92}$ and reverse $\mathrm{HHA}^{93}$

\section{DELAYED TREATMENT}

Treatment may be delayed if a patient does not seek immediate medical attention. These injuries are difficult to treat because malunion at the articular surface may have already set in and can impair outcomes. In general, fracture dislocations more than 3 weeks to 6 weeks old ${ }^{13,39,94}$ are considered chronic.

VPA, HHA, dynamic distraction external fixator, and silicon or pyrocarbon arthroplasties may be used for treatment of chronic injuries. VPA and $\mathrm{HHA}$, however, require an intact dorsal base of middle phalanx and may not be used for pilon fractures. ${ }^{13}$ Shen and colleagues ${ }^{13}$ reported treatment outcomes of DFD in 10 patients treated with dynamic distraction external fixation-performed at least 21 days after injury with good outcomes. Remodeling of the fracture occurs resulting in a concentric PIPJ articular surface with good function and painless ROM. Incomplete remodeling also may occur but does not impair function or cause pain. The key is early active ROM and edema control.

\section{SUPPLEMENTARY DATA}

Supplementary data related to this article can be found online at https://doi.org/10.1016/j.cps. 2019.03.005.

\section{REFERENCES}

1. Williams CS. Proximal interphalangeal joint fracture dislocations: stable and unstable. Hand Clin 2012; 28(3):409-16, xi.

2. Hastings $\mathrm{H}$ 2nd, Ernst JM. Dynamic external fixation for fractures of the proximal interphalangeal joint. Hand Clin 1993;9(4):659-74.

3. Kiefhaber TR, Stern PJ. Fracture dislocations of the proximal interphalangeal joint. J Hand Surg Am 1998;23(3):368-80.

4. Durham-Smith G, McCarten GM. Volar plate arthroplasty for closed proximal interphalangeal joint injuries. J Hand Surg Br 1992;17(4):422-8.

5. Tyser AR, Tsai MA, Parks BG, et al. Stability of acute dorsal fracture dislocations of the proximal interphalangeal joint: a biomechanical study. J Hand Surg Am 2014;39(1):13-8.

6. Cheah AE, Foo TL, Liao JC, et al. Post-reduction stability of the proximal interphalangeal joint after dorsal fracture dislocation-A cadaveric study. J Hand Surg Asian Pac Vol 2016;21(3):382-7. 
7. Bowers WH, Wolf JW Jr, Nehil JL, et al. The proximal interphalangeal joint volar plate. I. An anatomical and biomechanical study. J Hand Surg Am 1980; 5(1):79-88.

8. Caravaggi P, Shamian B, Uko L, et al. In vitro kinematics of the proximal interphalangeal joint in the finger after progressive disruption of the main supporting structures. Hand (N Y) 2015;10(3):425-32.

9. Bilos ZJ, Vender MI, Bonavolonta M, et al. Fracture subluxation of proximal interphalangeal joint treated by palmar plate advancement. J Hand Surg Am 1994;19(2): 189-95.

10. Janssen SJ, Molleman J, Guitton TG, et al. What middle phalanx base fracture characteristics are most reliable and useful for surgical decision-making? Clin Orthop Relat Res 2015;473(12):3943-50.

11. Donovan DS, Podolnick JD, Reizner W, et al. Accuracy and reliability of radiographic estimation of volar lip fragment size in PIP dorsal fracture-dislocations. Hand (N Y) 2018. 1558944718777831. [Epub ahead of print].

12. Haase SC, Chung KC. Current concepts in treatment of fracture-dislocations of the proximal interphalangeal joint. Plast Reconstr Surg 2014;134(6): 1246-57.

13. Shen XF, Mi JY, Rui YJ, et al. Delayed treatment of unstable proximal interphalangeal joint fracturedislocations with a dynamic external fixator. Injury 2015;46(10):1938-44.

14. Glickel SZ, Barron OA. Proximal interphalangeal joint fracture dislocations. Hand Clin 2000;16(3): 333-44.

15. Hastings $\mathrm{H}$ 2nd, Carroll C. Treatment of closed articular fractures of the metacarpophalangeal and proximal interphalangeal joints. Hand Clin 1988;4(3): 503-27.

16. Krakauer JD, Stern PJ. Hinged device for fractures involving the proximal interphalangeal joint. Clin Orthop Relat Res 1996;327:29-37.

17. Deitch MA, Kiefhaber TR, Comisar BR, et al. Dorsal fracture dislocations of the proximal interphalangeal joint: surgical complications and long-term results. J Hand Surg Am 1999;24(5):914-23.

18. Eaton RG, Malerich MM. Volar plate arthroplasty of the proximal interphalangeal joint: a review of ten years' experience. J Hand Surg Am 1980;5(3): 260-8.

19. Grant I, Berger AC, Tham SK. Internal fixation of unstable fracture dislocations of the proximal interphalangeal joint. J Hand Surg Br 2005;30(5):492-8.

20. Wilson JN, Rowland SA. Fracture-dislocation of the proximal interphalangeal joint of the finger. J Bone Joint Surg Am 1966;48(3):493-502.

21. Redler I, Williams JT. Rupture of a collateral ligament of the proximal interphalangeal joint of the fingers. Analysis of eighteen cases. J Bone Joint Surg Am 1967;49(2):322-6.
22. McCue FC, Honner R, Johnson MC, et al. Athletic injuries of the proximal interphalangeal joint requiring surgical treatment. J Bone Joint Surg Am 1970; 52(5):937-56.

23. Kato N, Nemoto K, Nakajima $H$, et al. Primary repair of the collateral ligament of the proximal interphalangeal joint using a suture anchor. Scand J Plast Reconstr Surg Hand Surg 2003;37(2):117-20.

24. Kato H, Minami A, Takahara M, et al. Surgical repair of acute collateral ligament injuries in digits with the Mitek bone suture anchor. J Hand Surg $\mathrm{Br}$ 1999; 24(1):70-5.

25. Lee SJ, Lee JH, Hwang IC, et al. Clinical outcomes of operative repair of complete rupture of the proximal interphalangeal joint collateral ligament: comparison with non-operative treatment. Acta Orthop Traumatol Turc 2017;51(1):44-8.

26. Freiberg A, Pollard BA, Macdonald MR, et al. Management of proximal interphalangeal joint injuries. Hand Clin 2006;22(3):235-42.

27. Boden RA, Srinivasan MS. Rotational dislocation of the proximal interphalangeal joint of the finger. J Bone Joint Surg Br 2008;90(3):385-6.

28. Frueh FS, Vogel P, Honigmann P. Irreducible dislocations of the proximal interphalangeal joint: algorithm for open reduction and soft-tissue repair. Plast Reconstr Surg Glob Open 2018;6(5):e1729.

29. Green SM, Posner MA. Irreducible dorsal dislocations of the proximal interphalangeal joint. J Hand Surg Am 1985;10(1):85-7.

30. Kung J, Touliopolis S, Caligiuri D. Irreducible dislocation of the proximal interphalangeal joint of a finger. J Hand Surg Br 1998;23(2):252.

31. Kjeldal I. Irreducible compound dorsal dislocations of the proximal interphalangeal joint of the finger. J Hand Surg Br 1986;11(1):49-50.

32. Oni OO. Irreducible buttonhole dislocation of the proximal interphalangeal joint of the finger (a case report). J Hand Surg Br 1985;10(1):100.

33. Posner MA, Wilenski M. Irreducible volar dislocation of the proximal interphalangeal joint of a finger caused by interposition of the intact central slip: a case report. J Bone Joint Surg Am 1978;60(1): 133-4.

34. Johnson FG, Greene MH. Another cause of irreducible dislocation of the proximal interphalangeal joint of a finger. J Bone Joint Surg Am 1966;48(3):542-4.

35. Cheung JP, Tse WL, Ho PC. Irreducible volar subluxation of the proximal interphalangeal joint due to radial collateral ligament interposition: case report and review of literature. Hand Surg 2015;20(1):153-7.

36. Whipple TL, Evans JP, Urbaniak JR. Irreducible dislocation of a finger joint in a child. A case report. J Bone Joint Surg Am 1980;62(5):832-3.

37. Peimer CA, Sullivan DJ, Wild DR. Palmar dislocation of the proximal interphalangeal joint. J Hand Surg Am 1984;9a(1):39-48. 
38. Schernberg F, Elzein F, Gillier P, et al. Dislocations of the proximal interphalangeal joints of the long fingers. Anatomo-clinical study and therapeutic results. Ann Chir Main 1982;1(1):18-28.

39. Burnier M, Awada T, Marin Braun F, et al. Treatment of unstable proximal interphalangeal joint fractures with hemi-hamate osteochondral autografts. J Hand Surg Eur Vol 2017;42(2):188-93.

40. Watanabe $K$, Kino $Y$, Yajima $H$. Factors affecting the functional results of open reduction and internal fixation for fracture-dislocations of the proximal interphalangeal joint. Hand Surg 2015;20(1): 107-14.

41. Maalla R, Youssef M, Ben Jdidia G, et al. Extensionblock pinning for fracture-dislocation of the proximal interphalangeal joint. Orthop Traumatol Surg Res 2012;98(5):559-63.

42. Newington DP, Davis TR, Barton NJ. The treatment of dorsal fracture-dislocation of the proximal interphalangeal joint by closed reduction and Kirschner wire fixation: a 16-year follow up. J Hand Surg $\mathrm{Br}$ 2001;26(6):537-40.

43. Dionysian E, Eaton RG. The long-term outcome of volar plate arthroplasty of the proximal interphalangeal joint. J Hand Surg Am 2000;25(3):429-37.

44. Duteille F, Pasquier P, Lim A, et al. Treatment of complex interphalangeal joint fractures with dynamic external traction: a series of 20 cases. Plast Reconstr Surg 2003;111(5):1623-9.

45. de Haseth KB, Neuhaus V, Mudgal CS. Dorsal fracture-dislocations of the proximal interphalangeal joint: evaluation of closed reduction and percutaneous Kirschner wire pinning. Hand (N Y) 2015; 10(1):88-93.

46. Waris E, Mattila S, Sillat T, et al. Extension block pinning for unstable proximal interphalangeal joint dorsal fracture dislocations. J Hand Surg Am 2016; 41(2):196-202.

47. Inoue G, Tamura Y. Treatment of fracture-dislocation of the proximal interphalangeal joint using extension-block Kirschner wire. Ann Chir Main Memb Super 1991;10(6):564-8.

48. Viegas SF. Extension block pinning for proximal interphalangeal joint fracture dislocations: preliminary report of a new technique. J Hand Surg Am 1992; 17(5):896-901.

49. Vitale MA, White NJ, Strauch RJ. A percutaneous technique to treat unstable dorsal fracturedislocations of the proximal interphalangeal joint. J Hand Surg Am 2011;36(9):1453-9.

50. Waris E, Alanen V. Percutaneous, intramedullary fracture reduction and extension block pinning for dorsal proximal interphalangeal fracture-dislocations. J Hand Surg Am 2010;35(12):2046-52.

51. Aladin A, Davis TR. Dorsal fracture-dislocation of the proximal interphalangeal joint: a comparative study of percutaneous Kirschner wire fixation versus open reduction and internal fixation. J Hand Surg Br 2005;30(2):120-8.

52. Weiss AP. Cerclage fixation for fracture dislocation of the proximal interphalangeal joint. Clin Orthop Relat Res 1996;327:21-8.

53. Cheah AE, Tan DM, Chong AK, et al. Volar plating for unstable proximal interphalangeal joint dorsal fracture-dislocations. J Hand Surg Am 2012;37(1): 28-33.

54. Ikeda M, Kobayashi Y, Saito I, et al. Open reduction and internal fixation for dorsal fracture dislocations of the proximal interphalangeal joint using a miniplate. Tech Hand Up Extrem Surg 2011;15(4): 219-24.

55. Kang GC, Yam A, Phoon ES, et al. The hook plate technique for fixation of phalangeal avulsion fractures. J Bone Joint Surg Am 2012;94(11):e72.

56. Hamilton SC, Stern PJ, Fassler PR, et al. Mini-screw fixation for the treatment of proximal interphalangeal joint dorsal fracture-dislocations. J Hand Surg Am 2006;31(8):1349-54.

57. Lee JY, Teoh LC. Dorsal fracture dislocations of the proximal interphalangeal joint treated by open reduction and interfragmentary screw fixation: indications, approaches and results. J Hand Surg $\mathrm{Br}$ 2006;31(2):138-46.

58. Lahav A, Teplitz GA, McCormack RR Jr. Percutaneous reduction and Kirschner-wire fixation of impacted intra-articular fractures and volar lip fractures of the proximal interphalangeal joint. Am J Orthop (Belle Mead NJ) 2005;34(2):62-5.

59. Eglseder WA, Jeter EC. Open reduction and internal fixation of proximal interphalangeal joint fracturesubluxations. Contemp Orthop 1992;24(1):45-50.

60. Green A, Smith J, Redding M, et al. Acute open reduction and rigid internal fixation of proximal interphalangeal joint fracture dislocation. J Hand Surg Am 1992;17(3):512-7.

61. Lee JY, Teoh LC, Seah VW. Extending the reach of the heterodigital arterialized flap by cross-finger transfer. Plast Reconstr Surg 2006;117(7):2320-8.

62. Cheah AE, Yao J. Surgical approaches to the proximal interphalangeal joint. J Hand Surg Am 2016; 41(2):294-305.

63. Foo GL, Ramruttun AK, Cheah AE, et al. Biomechanics of internal fixation modalities for middle phalangeal base fracture dislocation. J Hand Surg Asian Pac Vol 2017;22(1):14-7.

64. Chew WY, Cheah AE. Volar plate and screw fixation for dorsal fracture-dislocation of the proximal interphalangeal joint: case report. J Hand Surg Am 2010;35(6):928-30.

65. Gaul JS Jr, Rosenberg SN. Fracture-dislocation of the middle phalanx at the proximal interphalangeal joint: repair with a simple intradigital tractionfixation device. Am J Orthop (Belle Mead NJ) 1998;27(10):682-8. 
66. Agee JM. Unstable fracture dislocations of the proximal interphalangeal joint. Treatment with the force couple splint. Clin Orthop Relat Res 1987;214: 101-12.

67. Allison DM. Results in the treatment of fractures around the proximal interphalangeal joint with a pin and rubber traction system. J Hand Surg Br 1998; 23(5):700-1.

68. Bain GI, Mehta JA, Heptinstall RJ, et al. Dynamic external fixation for injuries of the proximal interphalangeal joint. J Bone Joint Surg $\mathrm{Br}$ 1998;80(6): 1014-9.

69. Deshmukh NV, Sonanis SV, Stothard J. Neglected volar dislocations of the interphalangeal joint. Hand Surg 2004;9(1):71-5.

70. Inanami H, Ninomiya S, Okutsu I, et al. Dynamic external finger fixator for fracture dislocation of the proximal interphalangeal joint. J Hand Surg Am 1993;18(1):160-4.

71. Majumder S, Peck F, Watson JS, et al. Lessons learned from the management of complex intraarticular fractures at the base of the middle phalanges of fingers. J Hand Surg $\mathrm{Br}$ 2003;28(6): 559-65.

72. Morgan JP, Gordon DA, Klug MS, et al. Dynamic digital traction for unstable comminuted intraarticular fracture-dislocations of the proximal interphalangeal joint. J Hand Surg Am 1995;20(4): 565-73.

73. Schenck RR. Classification of fractures and dislocations of the proximal interphalangeal joint. Hand Clin 1994;10(2):179-85.

74. Suzuki Y, Matsunaga T, Sato S, et al. The pins and rubbers traction system for treatment of comminuted intraarticular fractures and fracture-dislocations in the hand. J Hand Surg Br 1994;19(1):98-107.

75. de Soras X, de Mourgues P, Guinard D, et al. Pins and rubbers traction system. I Hand Surg $\mathrm{Br}$ 1997;22(6):730-5.

76. Hynes MC, Giddins GE. Dynamic external fixation for pilon fractures of the interphalangeal joints. J Hand Surg Br 2001;26(2):122-4.

77. Khan W, Fahmy N. The S-Quattro in the management of acute intraarticular phalangeal fractures of the hand. J Hand Surg Br 2006;31(1):79-92.

78. Ellis PR, Tsai TM. Management of the traumatized joint of the finger. Clin Plast Surg 1989;16(3):457-73.

79. Blazar PE, Robbe R, Lawton JN. Treatment of dorsal fracture/dislocations of the proximal interphalangeal joint by volar plate arthroplasty. Tech Hand Up Extrem Surg 2001;5(3):148-52.

80. Malerich MM, Eaton RG. The volar plate reconstruction for fracture-dislocation of the proximal interphalangeal joint. Hand Clin 1994;10(2):251-60.

81. Tyser AR, Tsai MA, Parks BG, et al. Biomechanical characteristics of hemi-hamate reconstruction versus volar plate arthroplasty in the treatment of dorsal fracture dislocations of the proximal interphalangeal joint. J Hand Surg Am 2015;40(2):329-32.

82. Calfee RP, Kiefhaber TR, Sommerkamp TG, et al. Hemi-hamate arthroplasty provides functional reconstruction of acute and chronic proximal interphalangeal fracture-dislocations. J Hand Surg Am 2009;34(7):1232-41.

83. Williams RM, Kiefhaber TR, Sommerkamp TG, et al. Treatment of unstable dorsal proximal interphalangeal fracture/dislocations using a hemi-hamate autograft. J Hand Surg Am 2003;28(5):856-65.

84. Afendras G, Abramo A, Mrkonjic A, et al. Hemihamate osteochondral transplantation in proximal interphalangeal dorsal fracture dislocations: a minimum 4 year follow-up in eight patients. J Hand Surg Eur Vol 2010;35(8):627-31.

85. Yang DS, Lee SK, Kim KJ, et al. Modified hemihamate arthroplasty technique for treatment of acute proximal interphalangeal joint fracture-dislocations. Ann Plast Surg 2014;72(4):411-6.

86. Korambayil PM, Francis A. Hemi-hamate arthroplasty for pilon fractures of finger. Indian J Plast Surg 2011;44(3):458-66.

87. Rozen WM, Niumsawatt $V$, Ross R, et al. The vascular basis of the hemi-hamate osteochondral free flap. Part 1: vascular anatomy and clinical correlation. Surg Radiol Anat 2013;35(7):585-94.

88. Rosenstadt BE, Glickel SZ, Lane LB, et al. Palmar fracture dislocation of the proximal interphalangeal joint. J Hand Surg Am 1998;23(5):811-20.

89. Meyer ZI, Goldfarb CA, Calfee RP, et al. The central slip fracture: results of operative treatment of volar fracture subluxations/dislocations of the proximal interphalangeal joint. J Hand Surg Am 2017;42(7): 572.e1-6.

90. Doering TA, Greenberg AS, Tuckman DV. Dorsal plating for intra-articular middle phalangeal base fractures with volar instability. Hand (N Y) 2018. 1558944718777868. [Epub ahead of print].

91. Tekkis PP, Kessaris N, Gavalas M, et al. The role of mini-fragment screw fixation in volar dislocations of the proximal interphalangeal joint. Arch Orthop Trauma Surg 2001;121(1-2):121-2.

92. Zhang $X$, Yang $L$, Shao $X$, et al. Treatment of bony boutonniere deformity with a loop wire. J Hand Surg Am 2011;36(6):1080-5.

93. Sinclair VF, Karantana A, Muir L. Reverse hemihamate arthroplasty for volar fracture dislocation of the proximal interphalangeal joint of the finger. J Hand Surg Eur Vol 2017;42(2):199-200.

94. Ruland RT, Hogan CJ, Cannon DL, et al. Use of dynamic distraction external fixation for unstable fracture-dislocations of the proximal interphalangeal joint. J Hand Surg Am 2008;33(1):19-25. 